\title{
Social impacts of road traffic: perceptions and priorities of local residents
}

\author{
Paulo Rui Anciaes \\ Centre for Transport Studies, University College London
}

Paul James Metcalfe

PJM Economics

Chris Heywood

Accent

This is an Accepted Manuscript of an article published by Taylor \& Francis Group in Impact Assessment and Project Appraisal on 26/12/2016, available online: http://www.tandfonline.com/doi/full/10.1080/14615517.2016.1269464

\begin{abstract}
The assessment of the social impacts of road traffic is usually based on objective indicators or on expert judgement, without input from the affected communities. This paper considers the perceptions and priorities of local residents about traffic impacts and possible mitigation measures, using as a case study a rural area that will be affected by traffic associated with the construction of a nuclear power station. The study consisted of a qualitative phase followed by a stated preference survey. Econometric models were used to measure the relative priority of different impacts and mitigation measures. The most impactful aspects were noise, vibration, and increased car or bus travel times. The most preferred measures were night-time restrictions to HGVs, parking restrictions, and safety measures for pedestrians and cyclists. There were significant differences in preferences according to residence location, gender, employment status, and household composition. The results provide information about aspects that tend to be aggregated in existing assessment frameworks, separating the reduction of the utility of some activities (like walking and driving) and the suppression of those activities.
\end{abstract}

\section{Keywords}

Social impacts of traffic; traffic impact assessment; traffic control; stated preference 


\section{Introduction}

Large roads and motorised traffic have several negative impacts on the population in surrounding areas. However, the range, nature, and size of these impacts depend on the perceptions of the individuals affected. Current frameworks for traffic impact assessment, such as the UK's IEA Guidelines (IEA 1993) and WebTAG (UK DFT 2014a; 2014b) rely on quantitative indicators of physical impacts and assess other impacts using qualitative information that is largely based on the judgement of the assessor. Those frameworks also do not consider the priorities of local communities regarding the level of the different impacts and possible mitigation measures. At a broader level, frameworks to assess transport policies, plans, and programs tend to focus on key environmental issues while the assessment of social impacts is in many cases indirect, qualitative, or simply reflected in the appraisal or planning assumptions (Fischer 1999, 2006).

This study looks at impacts of road traffic associated with the construction of a nuclear power station (Sizewell C) in a rural area in the East of England. It is anticipated that the 10-year construction project will increase traffic levels along the $7 \mathrm{~km}$ designated route, which links the A12 (a major road linking the region with London) and the site entrance, using the B1122 (a minor road) (Figure 1). The construction route would need to accommodate heavy goods vehicles (HGVs) delivering materials, abnormal loads, coaches transporting workers to the site, and private vehicles used by workers and visitors. The route crosses three villages (Yoxford, Middleton, and Theberton), with a total population of 1,348.

\section{Figure 1: Proposed route for the Sizewell C construction traffic}

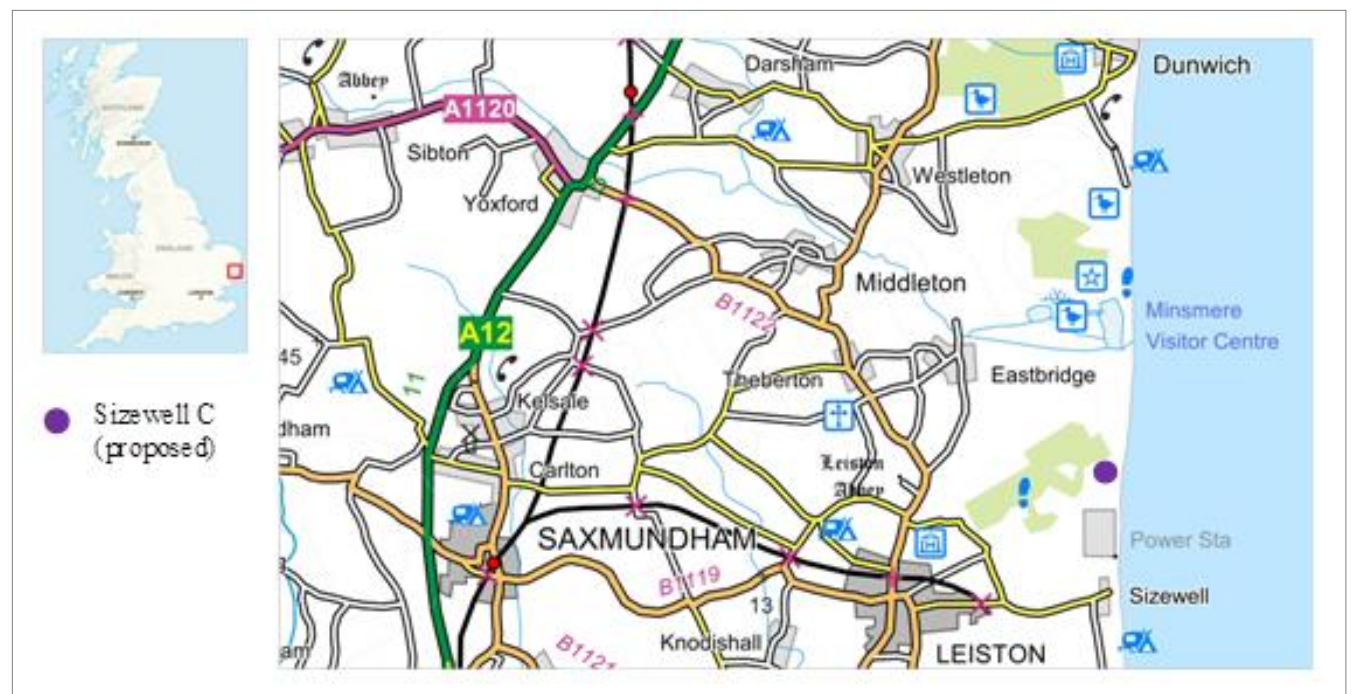

Base maps ( Copyright and Database Right 2016. Ordnance Survey (Digimap License) 
In the 1990s, the area was affected by road traffic associated with the construction of another power station (Sizewell B). Studies of the impacts of that project found that changes in perceptions throughout the lifespan of the project did not follow changes in objective indicators. In fact, the proportion of local residents identifying traffic as a problem in monitoring surveys, and the number of complaints and stories in the local press about traffic decreased after the first year of the construction project, despite the fact that traffic levels turned out to be higher than expected (Glasson et al. 1995; Glasson 2005).

The objective of this study was to analyse the perceptions about the potential traffic-related impacts of the Sizewell C project on the wellbeing of local communities, using in-depth interviews and a stated preference survey. More specifically the research answered the following questions:

a) what is the relative importance individuals attach to the different impacts of road traffic and to the different alternatives for mitigating those impacts?

b) what is the role of personal and situational factors in the formation of perceptions about the impacts?

c) what additional information can stated preference surveys provide to complement existing frameworks for the appraisal of the impacts of road traffic?

The rest of the paper is structured as follows. Section 2 reviews the evidence on the social impacts of road traffic and the methods to assess these impacts. Section 3 reports the results of the in-depth interviews. Section 4 describes the methods used in the design and analysis of the stated preference survey. The results of the survey are presented in sections 5 and 6 . Section 7 discusses how the results fit with previous literature and how the methods used complement those in usual frameworks for traffic impact assessment. Section 8 concludes the paper.

\section{Social impacts of road traffic}

The social impacts of transport can simply be defined as those that are not economic or environmental (UK DFT 2014a, p.1), or, more broadly, as the effects on the "preferences, wellbeing, behaviour or perception of individuals, groups, social categories and society in general (in the future") (Geurs et al. 2009). Motorised road traffic has a range of negative social impacts, well documented in the literature. For example, traffic creates air pollution and noise, which are linked with several health concerns (WHO 2005; Ndrepepa and Twardella 2011) and reduced well-being (Dratva et al. 2010; Orru et al. 2016). Increases in traffic levels also increase 
collision risk for cyclists (Reynolds et al. 2009) and pedestrians (Harwood et al. 2008). This may reduce the propensity for walking and cycling, leading to a reduction of physical activity and levels of accessibility to local facilities, and ultimately to social exclusion (SEU 2003) and to the deterioration of health and well-being (Egan et al. 2003; Mindell and Karlsen 2012). High traffic levels also separate communities, with potential effects on social cohesion (Appleyard et al.1981).

\subsection{Perceived impacts}

Perceptions about road traffic impacts do not depend only on traffic volumes. Traffic composition is often a determining factor, as heavy vehicles produce more noise and vibration, leading to higher annoyance levels (Paunović et al. 2009). The time of day is also relevant as high traffic levels create problems for pedestrians during the day time, but high traffic speeds produce loud noises at night-time, when it is most disruptive for local residents (Pirrera et al. 2010). The impacts also depend on location. The greater the distance from residences to the road, the lower the noise annoyance (Michaud et al. 2008) and the effect of traffic on pedestrian movement (Lassière 1976).

There is also evidence that individuals may not perceive the existing traffic levels as high or low in an absolute sense, but instead perceive changes in those levels. A review by Brown and Van Kamp (2009) concluded that when exposure to road traffic noise changes, individuals tend to show an excess response compared to the responses predicted from steady-state exposureresponse relationships. In other words, there is a "change effect" in addition to an "exposure effect". There is also a cumulative effect of the presence of several annoyances caused by traffic and other polluting activities. For example, Oiamo et al. (2015) found that noise and odour annoyances from traffic noise and air pollution have a combined effect on environmental and health-related quality of life.

There are also differences in the nature and intensity of the impacts felt by different groups. Children are particularly at risk to vehicle-pedestrian collisions and the elderly have the highest risk of mortality when involved in those collisions (Stoker et al. 2015). In addition, these two age groups are more vulnerable to the health impacts of air pollution (Makri and Stilianakis 2008) and noise (Van Kamp and Davies 2013). Road traffic is also responsible for the loss of children's independent mobility (Hillman et al. 1990) and for the reduction of walking levels of the elderly (Frost et al. 2010). Women are also more likely to be affected by traffic in terms 
of physical health (Gundersen et al. 2013), noise annoyance (Dratva et al. 2010), and walking and public transport accessibility (SEU 2003).

Mitigation measures may also be perceived as part of the problem, and not as a solution, if they are ineffective in reducing the traffic impact, or if they create other problems. The construction of bypasses often meets with protest due to concerns about the impacts on the local economy (Mills and Fricker 2011) or for environmental reasons (Bryant 1996). Road redesign and traffic calming schemes can also be unpopular among local residents due to the effects on vehicle flow. The construction or improvement of crossing facilities that are perceived as dangerous and unpleasant (such as footbridges and underpasses) may aggravate the barrier effect of the road (James et al. 2005) and noise barriers may limit the movement of pedestrians and cause visual intrusion (Herman et al. 1997; Arenas 2008)

\subsection{Appraisal frameworks and the measurement of perceptions and priorities}

In the UK, the traffic impacts of non-transport projects are assessed using the Guidelines for the Environmental Assessment of Road Traffic (IEA 1993). These guidelines apply when the total traffic flows are expected to increase by more than $30 \%$ overall or $10 \%$ in sensitive areas. It is assumed that these are the values above which individuals perceive changes in traffic levels, rather than having been empirically tested. Impacts are classified as "significant" or "not significant", but in many cases there are no rules defining thresholds of significance based on quantitative data, and the assessment is done using proxies or ad-hoc solutions. There is also no recommendation for using input from the affected communities.

Traffic impacts can also be assessed using frameworks for the appraisal of transport projects such as WebTAG (UK DFT 2014a; 2014b), which is in use in the UK. WebTAG focuses on tangible effects and not on the perceptions and averting behaviour of individuals affected by the project. For example, the assessment of accidents does not consider perceptions of risk or potential trip suppression and the assessment of noise does not consider the effect on indoor or outdoor activities. Some impacts, such as community severance and security, are assessed qualitatively only. The analysis also relies on census data, using areas that are too big for the correct estimation of the distributional effects of noise and air pollution. In addition, the impacts are not disaggregated for all groups. For example, gender is not considered. The analysis of noise and air pollution does not account for the effect on older people and the analysis of accidents, severance, and accessibility is not disaggregated by income group. There is also no guidance on how to assess projects with several different types of effects, which may lead to an 
underestimation of their overall impact, as it fails to account for the cumulative effects mentioned in the last section.

These limitations also apply to transport appraisal frameworks in use in other countries (Odgaard et al. 2005; Mackie and Worsley 2013). Some methods include input from the affected communities but are not required for all projects with major environmental or social impacts. For example, the Citizen Values Assessment developed in the Netherlands involves the construction of a "citizen values profile" where issues are ranked in order of importance for the community. The values are then translated into evaluation criteria, which are scored for each of the alternatives for a project (Stolp et al. 2002). The Community Impact Assessment framework in use in the USA (US DOT 1996) also uses community input to describe how several impacts are interrelated and distributed among different groups. Some transport authorities provide guidelines on how to collect that input, such as surveys where participants rate the importance of different impacts (Caltrans 2011, p. 117-121). Similar questions have also been used in studies done by community groups and activists (Transportation Alternatives 2006).

There is a growing academic literature on using surveys to measure the perceived effects of road traffic on quality of life (Yamazaki et al. 2005; Gundersen et al. 2013; Boniface et al. 2015). These studies produce a large number of variables, which can be analysed using multivariate statistics. For example, Kaplan (2001) used factor analysis to synthesize variables affecting people's satisfaction with physical and social aspects of their community and Mouette and Waisman (2004) used multiple correspondence analysis to model the effects of community severance as a hierarchical chain, where the effects at each level create conditions for the occurrence of effects at the next level.

The priorities of local residents can also be estimated using stated preference surveys, which ask individuals to choose among alternatives defined by a set of attributes. The willingness to trade-off marginal changes in each attribute can be derived from models of the choices. Caulfield and O'Mahony (2007) used this method to find that participants were willing to pay for a day time reduction of air pollution and a night-time reduction of noise. Stated preference surveys have also been used to estimate preferences regarding the ease of crossing roads, considering the characteristics of roads, traffic, and crossing facilities (Hensher et al. 2011; Meltofte and Nørby 2013; Cantillo et al. 2015). Other studies estimated preferences for mitigation measures (Eliasson et al. 2002; Garrod et al. 2002) and preferences regarding the size and duration of transport and non-transport disturbances (Willis and Garrod 1999). 
The present study builds on these efforts, by using a stated preference study to measure preferences about a wide range of potential traffic impacts and interventions to mitigate those impacts, identified in a preliminary qualitative study. This approach provides a more complete assessment of perceptions of individuals affected by road traffic, as previous research considered only specific types of impact in isolation. The method also identifies significant personal and situational factors explaining individual variations in perceptions about traffic.

\section{Qualitative stage}

The research started with a preliminary consultation survey to gain a general understanding about local views regarding the planned construction of the Sizewell C power station. A total of 267 local residents took part in this survey (122 face-to-face and 145 online). Construction traffic was perceived as the main concern about the project, mentioned by $85 \%$ of participants (comparing for example, with 23\% and 12\% mentioning "fear of leakage" and "against nuclear power", respectively). In addition, 70\% of participants stated that they expect to be dissatisfied living in their area because of the construction traffic and $18 \%$ expect to be satisfied. These results suggest that perceptions about construction traffic influence perceptions about the overall project, rather than the opposite.

Twenty of the participants in the consultation survey were then selected for in-depth interviews, to gain insight into how individuals would be impacted by the traffic and what interventions might help to mitigate against the impacts. The sample consisted of 10 participants who stated that they would be dissatisfied with the traffic in the preliminary survey, 6 who would be neither satisfied nor dissatisfied, and 4 who would be satisfied. 15 interviews were conducted face-to-face in homes and business premises and 5 were conducted by telephone.

Most (18) of the 20 participants were concerned about the impact of traffic on many aspects of their day-to-day life, mentioning several of the impacts identified in the literature, such as noise, air pollution, increased accident risk, and travel time losses. Some participants mentioned more general impacts without associating them with specific traffic aspects like noise or vibration. For example, some mentioned sleep disturbance and others anticipated that they would change their behaviour due to the presence of traffic, for example, by avoiding certain rooms in the house, or the garden, or by making fewer trips. 
"rather than popping to the shop 3-4 times a week to go and get a few bits for a couple of days. I'll do 1 big shop a week, I'll get everything I need, so just reduce the amount of time that I am on the road"

Participants also talked about aspects that are rarely mentioned in the literature and that reflect concerns specific to rural areas. This is, for example, the case of visual impacts of changes to the road infrastructure that are implemented to accommodate the increased traffic, such as the provision of street lighting.

"At the moment you can look up at the sky round here and you can see the stars when the clouds aren't there and it's beautiful. They're wanting to put street lights and everything in"

A common theme emerging from the interviews was the role of the characteristics of the road as an aggravating factor of traffic impacts. The volume of traffic was seen as too large for the local roads, which are narrow and go through residential areas. In particular, the problems of car accident risk arise not only because of increased traffic but because the road is not straight, decreasing visibility, especially for vehicles accessing properties.

"It looks fairly straight but there are bends and we have difficultly pulling out of our drives because we have very poor visibility. One of my neighbours [...] will come out to the other side of the road to tell [a family member] it's clear because she cannot see. If she pulls out when one of those lorries goes by I mean there's going to be an accident."

The impacts were associated with particular characteristics of the traffic. Traffic speed was identified as often as traffic volumes as the main concern of local residents. The duration of the works (10 years) was mentioned by all but one participant. There was also uncertainty regarding the distribution of traffic according to days of the week and times of the day, which prevented some participants from having a clear perception about the extent to which they would be affected.

"There's a lot of people with signs up that say...'We don't want an extra 600 trucks a day', in terms of traffic. Now I don't know where that figure of 600 came from. Is that day and night, or is it just during the day? How many days is that for? Is it just during the week? I've got no idea... "

The impact of traffic on wellbeing also depended on factors such as distance to the road, age, disability, concern with older family members and with children, employment status, and patterns of mobility: 
"I suppose if you're retired and here all day, you will notice it a lot more. I'm not, I'm out most of the time and here at weekends."

The most popular mitigation measures were speed restrictions and time-based traffic restrictions. Pedestrian crossings and bicycle lanes were also seen as having some potential to improve road safety. Several participants expressed doubts about the effectiveness of any mitigation measures, mentioning that the narrow roads and the proximity of dwellings along the proposed route would preclude consideration of interventions such as noise screening, pedestrian crossings, bicycle lanes, and widening of the roads. Participants living in areas where speed restrictions were already in place also expressed doubts about the enforcement of speed limits. Similarly, some were unsure of the benefits of time-based restrictions, as traffic would be compressed within the designated hours.

"You've got to be realistic. People won't do what they're told to do. They will still get in their car and go in and construction lorries will find the easiest route. Their sat nav will put them along the B1122."

"Trouble is, there's no pavement there because the house is right on the road [...] If there's no room for a pavement there's no room for a pedestrian crossing... I don't think a pedestrian crossing is feasible, and if it was, it would slow the traffic down."

"They put in acoustic secondary double glazing last time. You can't even open the windows because of the fumes and noise that comes in"

There were also contrasting opinions on the most appropriate hours for restricting traffic. Some people preferred day-time traffic to avoid sleep disturbance for residents close to the affected roads, whereas others favoured night time traffic to limit congestion during the day.

"I'd rather, I guess, [traffic was restricted] during the day - than obviously at night when you're trying to sleep"

"If you can get construction traffic away from peak time traffic, it can only be a good thing. I think that may be an option to think of, because people who are using that during the day, it's not gonna impact if they're coming in after 9 o'clock at night until, say, 6 in the morning. I don't know what the logistics would be because you need stuff during the day to be delivered."

\section{Stated preference survey: methods}

The main stage of the study was a stated preference survey to measure the relative importance local residents attach to the different impacts of the increased traffic and to the different 
possibilities for intervention. A letter was sent to all 775 dwellings in the parishes of Yoxford, Middleton, and Theberton, introducing the survey and including an open link to the online questionnaire. The survey questionnaire included questions about residence location, individual and household characteristics, and two stated preference exercises. In the first exercise respondents chose among alternative impacts and in the second exercise they chose among alternative mitigation measures. There were 105 completed questionnaires. The sample had a large proportion of older people and a fairly high income distribution (Error! Reference source not found.), reflecting the characteristics of rural areas in this part of the country.

The design of the survey used the MaxDiff approach, a type of Best-Worst scaling technique (Louviere et al. 2015). In this approach, participants are asked a sequence of questions where they choose their most and least preferred options among a subset of a large set of options. The subsets are varied in each question so that the sample as a whole contains a rich set of data on preferences between the options. This method is particularly indicated to derive robust preference scores for a list of items that is too long to ask participants to rank as a whole. It also has advantages over asking participants to rate each option on a scale, which tends to elicit a large number of high scores, not allowing for an understanding of the relative importance of each option. The MaxDiff method yields quantitative measures for each option which can be interpreted and understood with respect to their relative size as well as in terms of the order of importance.

The two stated preference exercises each consisted of six questions containing four options (impacts or mitigation measures) and a "none of these" alternative. The resulting datasets contain responses on the most and least preferred impact or mitigation measure within each set of four. This data was then exploded so that there were three choice situations modelled for each original choice situation asked about in the survey. The first of the new set of three indicated that the most preferred option was chosen from a choice set formed by the four options shown and the "none of these" option. The second and third observations were set up to indicate that each of the middle two options (not the most or least preferred) was individually preferred to the least preferred option in a pair-wise comparison. Thus, the best-worst design provided significantly more data for modelling than if participants had only been asked for their most preferred option. 
Table 1: Sample characteristics

\begin{tabular}{|c|c|c|}
\hline & \multirow{2}{*}{$\begin{array}{l}\% \\
97\end{array}$} \\
\hline Type & Residents & \\
\hline & Businesses & 3 \\
\hline \multirow[t]{3}{*}{ Parish } & Middleton & 19 \\
\hline & Theberton & 41 \\
\hline & Yoxford & 37 \\
\hline \multirow[t]{2}{*}{ Distance to road } & Near $(<100 \mathrm{~m}$ or $<1$ minute walk $)$ & 59 \\
\hline & Far $(>100 \mathrm{~m}$ and $>1$ minute walk) & 41 \\
\hline \multirow[t]{2}{*}{ Gender } & Male & 49 \\
\hline & Female & 51 \\
\hline \multirow[t]{6}{*}{ Age } & $16-35$ & 2 \\
\hline & $35-45$ & 5 \\
\hline & $45-55$ & 21 \\
\hline & $55-65$ & 30 \\
\hline & $65-75$ & 36 \\
\hline & $>75$ & 7 \\
\hline \multirow[t]{4}{*}{ Household type } & Without children (single adult) & 15 \\
\hline & Without children ( 2 or more adults) & 71 \\
\hline & With children aged $0-10$ & 9 \\
\hline & $\begin{array}{l}\text { With children aged 11-17 (and without children aged 0- } \\
\text { 10) }\end{array}$ & 5 \\
\hline \multirow[t]{3}{*}{ Employment status } & Full-time employment & 33 \\
\hline & Part-time employment & 11 \\
\hline & Other & 55 \\
\hline \multirow[t]{6}{*}{ Income per person } & Not stated & 10 \\
\hline & $<£ 7,500 /$ year & 13 \\
\hline & $£ 7,500-£ 12,500 /$ year & 21 \\
\hline & $£ 12,500-£ 17,500 /$ year & 28 \\
\hline & $£ 17,500-£ 25,000 /$ year & 20 \\
\hline & $>£ 25,000 /$ year & 9 \\
\hline
\end{tabular}

Note: Income per person was derived from answers to questions on household income and composition

The data was analysed via econometric models, using a conditional logit specification (McFadden 1973). This specification assumes that the utility of each option depends only on the attributes of that option. In the model for each of the two exercises, each option is entered as a dummy variable equal to 1 if the option is the corresponding impact or mitigation measure. The "none of these" option also entered the models as a dummy variable. One variable was omitted so as to serve as a reference point. All dummy variables entered the models with random coefficients with normal distributions. The model also contained interactions between the options and residence location of participants (village and distance from the road) and 
demographic variables (gender, age, household type, employment status, and income). Different classifications of these variables were tested. The final models use the classification yielding the greatest number of significant interactions.

The main outputs from the model are odds ratios measuring the relative likelihood that an option is chosen with, versus without, the impact or mitigation measure present in the model. They are calculated by taking the exponential of the coefficients in the model. The odds ratios were then rescaled in order to be relative to the impact or mitigation measure with the highest odds ratio. This was done by taking the exponential of the difference in the respective coefficients. The odds ratios then represent the relative importance of each impact or measure measured on a scale from 0 to 1 where 1 is the most preferred impact or mitigation measure.

\section{Traffic impacts}

The first exercise focused on the relative impact participants felt would be attached to different traffic aspects. The exercise consisted of six questions where participants chose the aspect of the increase in traffic would have the most and the least impact, from a set of four shown to them, drawn from a list of 16 possible impacts (Table 2). The list was constructed based on the results of the preliminary consultation survey and in-depth interviews. Some of the impacts were direct effects of traffic, such as air pollution, noise, vibration, visual impacts, and reduced mobility and accessibility (i.e. increased accident risk and travel times by different modes). Others were induced effects on well-being and behaviour, including avoid travelling (by specific modes of transport), avoid some areas (rooms or garden), individual impacts (on sleep, stress, and health), and impacts on the overall community.

Figure 2 shows an example of the type of question asked in this exercise. The set of impacts shown was different in all six questions. Participants could also choose an option stating that none of the four aspects would have an impact to them.

Table 3 shows the estimated conditional logit model of the choices made by participants. The model includes variables representing the impacts and the statistically significant interactions between the impacts and geographic and demographic and socio-economic variables. There were no significant interactions between impacts and the parish were participants live. 
Table 2: Traffic impacts

\begin{tabular}{ll} 
Name & Description \\
\hline airpol & Worsening of the local air quality \\
noise & Greater traffic noise \\
vibration & Greater vibration from traffic \\
visual & The sight of all the extra traffic \\
risk & Increased risk of being involved in an accident \\
walktriptime & Increased journey time when walking due to it taking longer to cross the road \\
carbustriptime & Extra time added to car or bus journeys, in particular exiting properties or at junctions \\
walkavoid & Not making walking trips that you would have otherwise made \\
caravoid & Not making driving trips that you would have otherwise made \\
bikeavoid & Not making cycling trips that you would have otherwise made \\
gardenavoid & Less time spent outside in garden \\
roomsavoid & Make some rooms in the house unusable \\
sleeping & Make sleeping more difficult \\
stress & Increased stress \\
health & Affect health \\
community & Loss of community cohesion or character \\
\hline
\end{tabular}

Figure 2: Choices of traffic impacts: example of question

\begin{tabular}{|c|} 
Which aspect of the increase in traffic would have the most impact on you, and which \\
would have the least impact? \\
Most impact \\
$\begin{array}{c}\text { Extra time added to your car or bus journeys, in } \\
\text { particular exiting properties or at junctions } \\
\text { Not making cycling trips that you would have } \\
\text { otherwise made }\end{array}$ \\
Not making driving trips that you would have \\
otherwise made \\
The sight of all the extra traffic \\
None of these would impact me
\end{tabular}


Table 3: Model of choices of traffic impacts

\begin{tabular}{|c|c|c|c|c|c|}
\hline $\begin{array}{l}\text { Variable } \\
\text { (options) }\end{array}$ & Coefficient & Std. error & $\begin{array}{l}\text { Variable } \\
\text { (interactions) }\end{array}$ & Coefficient & Std. error \\
\hline airpol & 1.068 & $0.260^{* * * *}$ & airpol_child & 1.425 & $0.539^{* * *}$ \\
\hline noise & 2.173 & $0.270^{* * * *}$ & airpol_lowinc & -1.780 & $0.672^{* * *}$ \\
\hline vibration & 2.135 & $0.277^{* * *}$ & vibration_far & -1.930 & $0.398^{* * *}$ \\
\hline visual & 0.596 & $0.241^{* *}$ & risk_child & 1.475 & $0.634^{* *}$ \\
\hline risk & 1.314 & $0.241^{* * *}$ & risk_highinc & 0.713 & $0.407^{*}$ \\
\hline walktriptime & - & - & walkavoid_ftwork & 0.614 & $0.334^{*}$ \\
\hline carbustriptime & 1.782 & $0.269^{* * * *}$ & caravoid_female & -0.736 & $0.324^{* *}$ \\
\hline walkavoid & 0.031 & 0.236 & caravoid_lowinc & 1.100 & $0.402^{* * *}$ \\
\hline caravoid & 0.877 & $0.273^{* * *}$ & bikeavoid_far & 0.766 & $0.437^{*}$ \\
\hline bikeavoid & -0.397 & 0.262 & bikeavoid_child & 1.055 & $0.461^{* *}$ \\
\hline stress & 1.205 & $0.259^{* * * *}$ & gardenavoid_older & -1.145 & $0.367^{* * * *}$ \\
\hline health & 0.587 & $0.231^{* *}$ & gardenavoid_lowinc & -1.208 & $0.618^{*}$ \\
\hline sleeping & 0.106 & 0.247 & roomsavoid_far & -1.609 & $0.512^{* * *}$ \\
\hline gardenavoid & 1.168 & $0.256^{* * *}$ & community_ftwork & 0.769 & $0.384^{* *}$ \\
\hline roomsavoid & -0.104 & 0.329 & none_far & 1.345 & $0.795^{*}$ \\
\hline community & 0.100 & 0.341 & & & \\
\hline none & -1.393 & $0.677^{* *}$ & & & \\
\hline
\end{tabular}

Observations:5480; Groups:104; Initial log-likelihood:-1504; final log-likelihood:-1475; Pseudo R ${ }^{2}$ : 0.190. Omitted impact: walktriptime. Interactions: far ( $>100 \mathrm{~m}$ and $>1$ minute from road), female, older (age $>65)$, child (household with children aged 0-10), ftwork (full-time employment), highinc (income per person> $£ 25,000 /$ year); lowinc (income per person $<£ 7,500 /$ year).

Most coefficients are precisely estimated and the Pseudo $\mathrm{R}^{2}$ statistic of 0.19 represents a good fit in this type of model (McFadden 1978, p.307). The highest coefficient is the one for the "noise" option, which means that in general, noise is the most important impact. The coefficient of the "none of these" option is significantly negative and lower than all other coefficients, which means that the probability of a participant choosing that option is smaller than the probabilities of choosing any particular impact. As expected, the coefficient of the "none of these" option is less negative for participants living far from the road.

Table 4 shows the odds ratios for each impact, calculated from the model above. The odds ratios are relative to the most important impact (noise). The values are sorted by descending order. The values in the "base" column are the ratios for a reference group of participants who live near the road, are male, less than 65 years old, have no children, are not in full time employment, and have middle income. The other columns are the ratios for participants who are not in that reference group, that is, those who live near the road or who are female, older 
than 65, have children, are in full time employment, or have high or low income. The ratios for these participants are only shown when they differ from the ones of the reference group.

Table 4: Odds ratios of traffic impacts

\begin{tabular}{|c|c|c|c|c|c|c|c|c|}
\hline Name & Base & Far & Female & Older & $\begin{array}{c}\text { With } \\
\text { children }\end{array}$ & $\begin{array}{c}\text { FT } \\
\text { work }\end{array}$ & $\begin{array}{l}\text { High } \\
\text { income }\end{array}$ & $\begin{array}{c}\text { Low } \\
\text { income }\end{array}$ \\
\hline noise & 1.00 & & & & & & & \\
\hline vibration & 0.96 & 0.14 & & & & & & \\
\hline carbustriptime & 0.68 & & & & & & & \\
\hline risk & 0.42 & & & & 1.85 & & 0.86 & \\
\hline stress & 0.38 & & & & & & & \\
\hline gardenavoid & 0.37 & & & 0.12 & & & & 0.11 \\
\hline airpol & 0.33 & & & & 1.38 & & & 0.06 \\
\hline caravoid & 0.27 & & 0.13 & & & & & 0.82 \\
\hline visual & 0.21 & & & & & & & \\
\hline health & 0.20 & & & & & & & \\
\hline sleeping & 0.13 & & & & & & & \\
\hline community & 0.13 & & & & & 0.27 & & \\
\hline walkavoid & 0.12 & & & & & 0.22 & & \\
\hline walktriptime & 0.11 & & & & & & & \\
\hline roomsavoid & 0.10 & 0.02 & & & & & & \\
\hline bikeavoid & 0.08 & 0.16 & & & 0.22 & & & \\
\hline
\end{tabular}

The most impactful traffic aspects for the reference group, after noise, were vibration (odds ratio of 0.96) and extra time added to car or bus journeys (0.68). All the other impacts had an odds ratio below 0.5 . The least impactful aspects were avoiding cycling trips (0.08) and avoiding some rooms in the house (0.10). Participants living far from the road had different preferences, as they were much less concerned with vibration and slightly more concerned about avoiding trips by bicycle and less concerned about avoiding some rooms in the house, compared to participants living near the road.

Gender was only significant for the "avoid car trips" impact (females were less concerned with this problem than males) and age was only significant for the "avoid garden" impact (older participants were less concerned with this problem than younger participants). Household structure was a more relevant factor than age and gender differentiating between the preferences within the sample. The main concerns for participants in households with children were accident risk and air pollution, which were both more important than noise (i.e. had an odds ratio higher than 1). These participants were also more concerned with avoiding bicycle trips 
than those in other types of households. Individuals in full time employment were more concerned with the loss of community character and suppressed walking trips, compared with other participants. Individuals with high income attached more importance to accident risk, and those with low income attached more importance to suppressed car trips and less importance to air pollution and avoiding the garden, compared with those with middle income.

\section{Traffic mitigation measures}

The second stated preference exercise focused on the relative priority participants attached to different interventions to mitigate the impacts of increased traffic. The exercise consisted of six questions where participants chose the measure they would like to see given the highest priority and the measure they would like to see given the lowest priority. Each question showed four measures, drawn from a list of sixteen (Table 5). The measures include shorter duration of construction works, restrictions to the circulation of certain types of vehicles (light goods vehicles (LGVs) or heavy goods vehicles (HGVs)) at certain times (peak, weekend, or nighttime), other restrictions (to routes used by cars or LGVs, traffic speeds, or parking), and general measures not aimed directly at construction traffic (safety measures for pedestrians, cyclists, and car drivers, air quality standards, noise reduction measures for properties, and street lighting).

Figure 3 shows an example of the type of question asked in this exercise. The set of measures shown was different in all six questions. Participants could also choose an option stating that none of the four measures was important to them.

Table 6 shows the estimated conditional logit model. The model includes the variables representing the mitigation measures and the statistically significant interactions between measures and geographic and demographic and socio-economic variables. Unlike in the first stated preference exercise, there were no significant income interactions, but there was one significant interaction with parish of residence. Most coefficients are precisely estimated and the Pseudo $\mathrm{R}^{2}$ statistic is satisfactory. The highest coefficient is the one for the night-time restrictions to HGVs, which means that in general, this is the preferred mitigation measure for local residents. The coefficient of the "none of these" option is statistically insignificant and lower than all other coefficients. 
Table 5: Mitigation measures

\begin{tabular}{ll} 
Name & Description \\
\hline quick & Construction completed as quickly as possible, but with higher daily traffic flows \\
peak_lgv & Peak hour restrictions on movements of LGVs \\
weekend_lgv & Weekend restrictions on movements of LGVs \\
night_lgv & Night-time restrictions on movements of LGVs \\
peak_hgv & Peak hour restrictions on movements of HGVs \\
weekend_hgv & Weekend restrictions on movements of HGVs \\
night_hgv & Night-time restrictions on movements of HGVs \\
route_lgv & Requiring light goods vehicles to take particular routes to site \\
route_car & Requiring car drivers who live east of the A12 to take particular routes to site \\
speed & Strict enforcement of speed limits \\
parking & Less onsite parking resulting in fewer cars, but more buses, travelling direct to \\
& site \\
safe_walk & Provision of safety measures for pedestrians and cyclists \\
safe_car & Provision of safety measures for private accesses to properties \\
airpol & Maintenance of current air quality standards \\
noise & Provision of noise reduction measures for properties \\
lighting & Provision of street lighting \\
\hline
\end{tabular}

Figure 3: Choices of mitigation measures: example of question

\begin{tabular}{|c|c|c|}
\hline \multicolumn{3}{|c|}{$\begin{array}{l}\text { Which of these measures would you like to see given the highest priority, and which } \\
\text { would you like to see given the lowest priority? }\end{array}$} \\
\hline Highest priority & & Lowest priority \\
\hline$\ominus$ & $\begin{array}{l}\text { Provision of safety measures for pedestrians and } \\
\text { cyclists }\end{array}$ & $\odot$ \\
\hline • & $\begin{array}{l}\text { Nighttime }(22: 00-07: 00) \text { restrictions on } \\
\text { movements of heavy goods vehicles }\end{array}$ & $\ominus$ \\
\hline$\ominus$ & $\begin{array}{l}\text { Nighttime (22:00 - } 07: 00) \text { restrictions on } \\
\text { movements of light goods vehicles }\end{array}$ & $\ominus$ \\
\hline$\theta$ & $\begin{array}{l}\text { Provision of less onsite parking resulting in fewer } \\
\text { cars, but more buses, travelling direct to site }\end{array}$ & $\ominus$ \\
\hline
\end{tabular}


Table 6: Model of choices of mitigation measures

\begin{tabular}{|c|c|c|c|c|c|}
\hline Variable & coefficient & std. error & Variable & coefficient & std. error \\
\hline quick & 1.127 & $0.452^{* *}$ & quick_far & 1.292 & $0.382^{* * *}$ \\
\hline peak_lgv & 1.741 & $0.436^{* * *}$ & quick_older & 0.982 & $0.402^{* *}$ \\
\hline weekend_lgv & 2.390 & $0.377^{* * *}$ & quick_child & 1.509 & $0.620^{* *}$ \\
\hline night_lgv & 3.107 & $0.350^{* * *}$ & peak_lgv_female & 0.998 & $0.369^{* * *}$ \\
\hline peak_hgv & 2.317 & $0.416^{* * *}$ & peak_lgv_child & 1.448 & $0.625^{* *}$ \\
\hline weekend_hgv & 2.837 & $0.440^{* * *}$ & weekend_lgv_ftwork & 0.797 & $0.327^{* *}$ \\
\hline night_hgv & 3.844 & $0.391^{* * *}$ & peak_hgv_female & 0.722 & $0.354^{* *}$ \\
\hline parking & 3.639 & $0.351^{* * *}$ & peak_hgv_ftwork & 0.639 & $0.369^{*}$ \\
\hline route_lgv & 2.871 & $0.357^{* * *}$ & weekend_hgv_female & 1.040 & $0.390^{* * *}$ \\
\hline route_car & 2.702 & $0.424^{* * *}$ & weekend_hgv_ftwork & 1.144 & $0.366^{* * *}$ \\
\hline speed & 3.051 & $0.452^{* * *}$ & speed_older & 1.008 & $0.422^{* *}$ \\
\hline noise & 1.845 & $0.402^{* * *}$ & noise_female & 0.854 & $0.446^{*}$ \\
\hline safe_walk & 3.409 & $0.347^{* * *}$ & noise_child & 1.265 & $0.499^{* *}$ \\
\hline safe_car & 1.688 & $0.435^{* * *}$ & safe_car_female & 1.614 & $0.502^{* * *}$ \\
\hline air & 2.239 & $0.418^{* * *}$ & safe_car_child & 1.690 & $0.868^{*}$ \\
\hline light & - & - & air_female & 0.817 & $0.435^{*}$ \\
\hline none & 0.381 & 0.440 & route_car_yoxford & -0.550 & $0.327^{*}$ \\
\hline
\end{tabular}

Observations:5410; Groups:101; Initial log-likelihood -1420; final log-likelihood:-1394; Pseudo R²: 0.226

Omitted measure: light. Interactions: as in Table 3

Table 7 shows the odds ratios for each of the measures, in relation to night-time restrictions to HGVs (which was the highest priority measure overall). The values are sorted by descending order. The "base" values for each measure are the odds ratios for the same reference group as in the first exercise, and the values in other columns are those for other participants, in the cases where they differ from the values of the reference group.

The highest priority measures for the reference group, after night-time restrictions to HGVs, were provision of less on-site parking (odds ratio of 0.81 ) and safety measures for pedestrians and cyclists (0.65). All the other measures had an odds ratio below 0.5. The least important measures were the provision of street lighting (0.02), followed by construction works completed as quickly as possible (0.07). Participants living far from the road have a higher priority for quick construction works than those living near. Participants in Yoxford gave a lower priority to routeing restrictions to cars. This result may be explained by a lower concern about "rat running", as Yoxford is located on the A12, while the other villages are located on minor roads (see Figure 1).

Gender was a highly significant factor differentiating priority scores in the sample. Women were more likely than men to prioritise measures such as peak restrictions to LGVs and HGVs, 
weekend restrictions to $\mathrm{HGVs}$, noise reduction measures for properties, safety measures for private access to properties, and air quality standards, all relative to night-time restrictions to HGVs. The main priority for older participants was the enforcement of speed limits, which was more important than night-time restrictions to $\mathrm{HGVs}$ (i.e. have an odds ratio higher than 1). Older participants also gave a higher priority to quick construction works than those in other age groups. Individuals in households with children attached a higher priority to noise measures to properties, peak restrictions to LGVs, safety measures for private accesses to properties, and quick constructions works, compared to participants in other types of households. The main priority for participants in full-time employment is weekend restrictions to HGVs (odds ratio of 1.15). These participants also attach greater priority to weekend restrictions to LGVs and to peak time restrictions to HGVs, compared with other participants.

Table 7: Odds ratios of mitigation measures

\begin{tabular}{|c|c|c|c|c|c|c|c|}
\hline Name & Base & Far & Yoxford & Female & Older & $\begin{array}{c}\text { With } \\
\text { children }\end{array}$ & $\begin{array}{c}\text { FT } \\
\text { work }\end{array}$ \\
\hline night_hgv & 1.00 & & & & & & \\
\hline parking & 0.81 & & & & & & \\
\hline safe_walk & 0.65 & & & & & & \\
\hline night_lgv & 0.48 & & & & & & \\
\hline speed & 0.45 & & & & 1.24 & & \\
\hline route_lgv & 0.38 & & & & & & \\
\hline weekend_hgv & 0.37 & & & 1.03 & & & 1.15 \\
\hline route_car & 0.32 & & 0.18 & & & & \\
\hline weekend_lgv & 0.23 & & & & & & 0.52 \\
\hline peak_hgv & 0.22 & & & 0.45 & & & 0.41 \\
\hline air & 0.20 & & & 0.45 & & & \\
\hline noise & 0.14 & & & 0.32 & & 0.48 & \\
\hline peak_lgv & 0.12 & & & 0.33 & & 0.52 & \\
\hline safe_car & 0.12 & & & 0.58 & & 0.63 & \\
\hline quick & 0.07 & 0.24 & & & 0.18 & 0.30 & \\
\hline light & 0.02 & & & & & & \\
\hline
\end{tabular}

\section{Discussion}

The results confirm that perceptions of local residents about the problems created by increased traffic levels in their communities, and about solutions to those problems, depends on the characteristics of traffic (such as traffic composition) and time of day. For example, exposure to noise was identified as the main impact of the increased traffic levels but noise reduction 
measures for properties were not rated as a high priority measure, when compared to measures such as traffic restrictions at night-time and on weekends. In addition, traffic restrictions on HGVs were perceived as considerably more important than restrictions on LGVs and cars. These results suggest that it is possible to implement solutions that reduce the perceived impact of traffic without limiting total daily traffic levels. For example, Brown (2014) reports a case where a traffic management strategy improved residents' reported levels of noise annoyance not by reducing noise levels but by reducing the number of noisy events at night-time.

The study also found significant variations in the impacts perceived by different groups within the same community. Individuals in households with children were more concerned with accident risk, air pollution, and suppressed cycling trips, which is explained by the fact that children are particularly vulnerable to air pollution and at risk of being involved in road accidents while walking or playing outside, as mentioned in Section 2. Although the differences between the impacts perceived by younger and older adults were not as marked as those found in previous literature, the present study found that the main priority for older participants was the enforcement of speed limits, which may reflect their concern about not being able to cross the road safely. Employment status is also relevant, as individuals in full-time employment were particularly supportive traffic restrictions on weekends (when they are more likely to spend time at home) and on peak hours (when they are more likely to drive or use buses).

The results can also be interpreted in relation to the assessment frameworks discussed in Section 2, such as WebTAG. The aspects with the highest impact scores (as expressed by odds ratios) were the ones that are included in WebTAG (for example, noise, vibration, travel time, and accident risk). However, WebTAG aggregates impacts that have different degrees of importance depending on the context. For example, vibration is not considered as a separate impact, being assessed together with noise. However, the present study found that vibration is much less important than noise for people far from the road (the impact score of vibration comparing to noise was 0.96 for residents living close to the road but only 0.14 for those living far). There are other aspects (such as stress and visual impacts), that were found to be important but that are not considered separately in WebTAG and only partly overlap some of the impacts included in that assessment framework.

There are also differences in the perceived impact of traffic in terms of reduction of the utility derived from some activities (such as travelling) and the suppression of those activities. For example, increased risk of accidents (impact score $=0.42$ ) and increased time to car/bus journeys (impact score $=0.68$ ) were judged to be more impactful than the suppression of driving trips 
(impact score $=0.27$ ). This is probably due to the fact that participants only stop driving when the associated utility falls below a certain threshold, due to the accident risk and time losses. In contrast, the increased time for walking trips is perceived as important as the suppression of those trips (impact scores of 0.11 and 0.12 respectively), which suggests that people will stop walking for relatively low increases in walking trip time and in other negative impacts of traffic on walking. In both cases (driving and walking), the analysis of the differences between the two types of impacts provides detail that is difficult to obtain using the WebTAG approach, which, as mentioned previously, does not measure averting behaviour, and measures the impact of traffic on driving and walking in a series of different and overlapping assessments, related to travel time, accessibility, severance, and journey quality.

In some cases, the consideration of impacts on different modes of transport also allows for a better understanding of some WebTAG impacts. For example, the WebTAG approach is to treat severance (the barrier effect of traffic on local transport) as a problem affecting nonmotorised modes. However, the results of this study suggests that the severance is more of a problem for car users than for pedestrians and cyclists, as the impact score of the "avoid car trips" impact (0.27) is higher than the scores of "avoid walking trips" (0.12) and "avoid cycle trips" (0.08).

\section{Conclusions}

This paper analysed the perceptions and priorities about the social impacts of road traffic associated with a large construction project. A qualitative study found that local residents were concerned not only with overall traffic levels but also with the characteristics of both traffic and roads. In addition, there was no consensus regarding the most effective measures to mitigate the negative impacts. The main stated preference survey revealed that the most impactful aspects were noise, vibration, and increased car or bus travel times, but there were differences according to distance from the road, and individual characteristics (especially household composition and income). The mitigation measures given highest priority were night-time restrictions to HGVs, provision of less onsite parking, and provision of safety measures for pedestrians and cyclists. Gender and household composition were the main factors differentiating preferences.

The method used complements the objective and expert-based information provided by existing frameworks to assess the impacts of traffic, as it provides additional detail on the perceptions about specific aspects that are often combined with other aspects, or not 
disaggregated for all relevant groups and by distance from residences to the road. The method can also be used to examine the differences between perceptions before traffic increases and actual experiences after those increases.

\section{Acknowledgements}

This work was supported by Suffolk County Council

\section{References}

Appleyard, D., Gerson, M S., Lintell, M. (1981) Livable Streets. University of California Press, Berkeley. Arenas, J P. (2008) Potential problems with environmental sound barriers when used in mitigating surface transportation noise. Science of the Total Environment 405 (1-3),173-179.

Boniface, S., Scholes, S., Dhanani, A., Anciaes, P R., Vaughan L., Mindell, J S. (2015) Is community severance a public health problem? Evidence from the Street Mobility project's two London case studies. Journal of Transport and Health 2 (2), S34-S35.

Brown, A L. (2014) Longitudinal annoyance responses to a road traffic noise management strategy that reduced heavy vehicles at night. Journal of the Acoustical Society of America 137 (1), 165-176.

Brown, A L., Van Kamp, I. (2009) Response to a change in transport noise exposure: a review of evidence of a change effect. Journal of the Acoustical Society of America 125 (3), 3018-3029.

Bryant, B. (1996) Twyford Down: Roads, Campaigning and Environmental Law. E \& FN Spon, London.

Caltrans (California Department of Transportation) (2011) Standard environmental reference handbook. Volume 4: community impact assessment. Available from http://www.caltrans.ca.gov/ser/vol4/vol4.htm

Cantillo, V., Arellana, J., Rolong, M. (2015) Modelling pedestrian crossing behaviour in urban roads: a latent variable approach. Transportation Research F 32, 56-67.

Caulfield, B., O’Mahony, M. (2007) Evaluating the economic cost of air and noise pollution generated by $\begin{array}{lllll}\text { transport. } & \text { AET } & \text { Papers } & \text { Repository. } & \text { Available }\end{array}$ http://abstracts.aetransport.org/paper/index/id/2770/confid/13

Dratva, J., Zemp, E., Dietrich, D F., Bridevaux, P-O., Rochat, T., Schindler, C., Gerbase, M W. (2010) Impact of road traffic noise annoyance on health-related quality of life: results from a population-based study. Quality of Life Research 19 (1), 37-46.

Eliasson, J., Dillén, J L., Widell, J. (2002) Measuring intrusion valuations through stated preferences and hedonic prices - a comparative study. AET Papers Repository. Available from http://abstracts.aetransport.org/paper/download/id/1359

Fischer, T B. (1999) Comparative analysis of environmental and socio-economic impacts in SEA for transport related policies, plans, and programs. Environmental Impact Assessment Review 19 (3), 275-303. 
Fischer, T B. (2006) Strategic environmental assessment and transport planning: towards a generic framework for evaluating practice and developing guidance. Impact Assessment and Project Appraisal $\mathbf{2 4}$ (3), 183-197.

Frost, S S., Goins, R T., Hunter, R H., Hooker, S P., Bryant, L L., Kruger, J., Pluto, D. (2010) Effects of the built environment on physical activity of adults living in rural settings. American Journal of Health Promotion 24 (4), 267-283.

Garrod, G D., Scarpa, R., Willis, K G. (2002) Estimating the benefits of traffic calming on through routes: a choice experiment approach. Journal of Transport Economics and Policy 36 (2), 211-231.

Geurs, K T., Boon, W., Van Wee, B. (2009) Social impacts of transport: literature review and the state of the practice of transport appraisal in the Netherlands and the United Kingdom. Transport Reviews 29 (1), 6990.

Glasson, J. (2005) Better monitoring for better impact management: the local socio-economic impacts of constructing Sizewell B nuclear power station. Impact Assessment and Project Appraisal 23 (3), 215-226.

Glasson, J., Chadwick, A., Therivel, R. (1995) The local socio-economic impacts of the Sizewell 'B' PWR power station construction project, 1987-1995 - Summary report. Impacts Assessment Unit, School of Planning, Oxford Polytechnic, Oxford.

Gundersen, H., Magerøy, N., Moen, B E., Bråtveit, M. (2013) Traffic density in area of residence is associated with health-related quality of life in women - the community-based Hordaland Health Study. Archives of Environmental and Occupational Health 68 (3), 153-160.

Harwood, D W., Torbic, D J., Gilmore, D K., Bokenkroger, C D., Dunn, J M., Zegeer, C V., Srinivasan, R., Carter, D., Raborn, C., Lyon, C., Persaud, B. (2008) Pedestrian safety prediction methodology. Final report for NCHRP Project 17-26. Available from http://onlinepubs.trb.org/onlinepubs/nchrp/nchrp w129p3.pdf

Hensher, D A., Rose, J M., Ortúzar, J de D., Rizzi, L I. (2011) Estimating the value of risk reduction for pedestrians in the road environment: an exploratory analysis. Journal of Choice Modelling 4 (2), 70-94.

Herman, L A., Finney, M A., Clum, C M., Pinckney, E W. (1997) Perception of traffic noise barrier effectiveness: Public opinion survey of residents living near I-71. Transportation Research Record 1601, 49-54.

Hillman, M., Adams, J., Whitelegg, J. (1990) One false move... a study of children's independent mobility. Policy Studies Institute, London. Available from http://john-adams.co.uk/wpcontent/uploads/2007/11/one\%20false $\% 20$ move.pdf

IEA (Institute of Environmental Assessment) (1993) Guidelines for the Environmental Assessment of Road Traffic. IEA, London.

James, E., Millington, A., Tomlinson, P. (2005) Understanding community severance Part 1: views of practitioners and communities. Report for UK Department for Transport. Available from http://webarchive.nationalarchives.gov.uk/+http://www.dft.gov.uk/adobepdf/163944/Understanding_Co mmunity_Sev1.pdf

Kaplan, R. (2001) The nature of the view from home: psychological benefits. Environment and Behavior 33 (4), 507-542. 
Lassière, A. (1976) The environmental evaluation of transport plans. UK Department of Environment, [S.I.]

Louviere, J., Flynn, T., Marley, A. (2015) Best-worst Scaling: Theory, Methods and Applications. Cambridge University Press, Cambridge.

Mackie, P., Worsley, T. (2013) International comparisons of transport appraisal practice - Overview report. Report to UK Department for Transport. Institute for Transport Studies, University of Leeds, Leeds. Available from https://www.gov.uk/government/uploads/system/uploads/attachment_data/file/209530/ final-overview-report.pdf

Makri, A., Stilianakis, N I. (2008) Vulnerability to air pollution health effects. International Journal of Hygiene and Environmental Health 211 (3-4), 326-336.

McFadden, D. (1973) Conditional logit analysis of qualitative choice behavior. In P Zarembka (Ed.) Frontiers in Econometrics. Academic Press, New York; pp.105-142.

McFadden, D. (1978) Quantitative methods for analysing travel behaviour of individuals: some recent developments. In D A Hensher and P R Stopher (Eds). Behavioural Travel Modelling. Croom Helm, London; pp. 279-318.

Meltofte, K R., Nørby, L E. (2013) Vejen som barriere for fodgængere [The road as a barrier for pedestrians]. Trafikdage på Aalborg Universitet 2013. Available from http://www.trafikdage.dk/td/papers/papers13/KatrineRabjergMeltofte.pdf [Proceedings from the Annual Transport Conference at Aalborg University] [in Danish].

Michaud, D S., Keith, S E., McMurchy, D. (2008) Annoyance and disturbance of daily activities from road traffic noise in Canada. Journal of the Acoustical Society of America 123 (2), 784-792.

Mills, J., Fricker, J. (2011) Integrated analysis of economic impacts of bypasses on communities - panel data analysis and case study interviews. Transportation Research Record 2242, 114-121.

Mindell, J S., Karlsen, S. (2012) Community severance and health: what do we actually know? Journal of Urban Health 89 (2), 232-246.

Mouette, D., Waisman, J. (2004) Proposta de uma metodologia de avaliação do efeito barreira [A proposed method for evaluating the barrier effect]. Revista dos Transportes Públicos 102, 33-54. Available from http://www.antp.org.br/5dotSystem/download/dcmDocument/2013/01/10/B9BD823A-1D2B-4ED280F9-A44BB52404F6.pdf [in Portuguese]

Ndrepepa, A., Twardella, D. (2011) Relationship between noise annoyance from road traffic noise and cardiovascular diseases: a meta-analysis. Noise and Health 13 (52), 251-259.

Odgaard, T., Kelly, C., Laird, J. (2005). Current practice in project appraisal in Europe - Analysis of country reports. HEATCO Project Deliverable 1. Available from http://heatco.ier.uni-stuttgart.de/hd1 final.pdf

Oiamo, T H., Luginaah, I N., Baxter, J. (2015) Cumulative effects of noise and odour annoyances on environmental and health related quality of life. Social Science and Medicine 146, 191-203.

Orru, K., Orru, H., Maasikmets, M., Hendrikson, R., Ainsaar, M. (2016) Well-being and environmental quality: does pollution affect life satisfaction? Quality of Life Research 25 (3), 699-705.

Paunović, K., Jakovljević, B., Belojević, G. (2009). Predictors of noise annoyance in noisy and quiet urban streets. Science of the Total Environment 407 (12), 3707-3711. 
Pirrera, S., De Valck., E, Cluydts., R. (2010) Nocturnal road traffic noise: a review on its assessment and consequences on sleep and health. Environment International 36 (5), 492-498.

Reynolds, C O., Harris, M A., Teschke, K., Cripton, P A., Winters, M. (2009) The impact of transportation infrastructure on bicycling injuries and crashes: a review of the literature. Environmental Health 8:47. Available from http://www.ehjournal.net/content/8/1/47

SEU (Social Exclusion Unit) (2003) Making the connections: final report on transport and social exclusion. Stationery Office, London. Available from http://assets.dft.gov.uk/statistics/series/accessibility/makingthe-connections.pdf

Stoker, P., Garfinkel-Castro, A., Khayesi, M., Odero, W., Mwangi, M N., Peden, M., Ewing, R. (2015). Pedestrian safety and the built environment: a review of the risk factors. Journal of Planning Literature 30 (4), 377-392.

Stolp, A., Groen, W., Van Vliet, J., Vanclay, F. (2002) Citizen values assessment: incorporating citizens' value judgements in environmental impact assessment. Impact Assessment and Project Appraisal 20 (1), 11-23. Transportation Alternatives (2006) Traffic's human toll - a survey of the impacts of vehicular traffic on New York City residents. Available from http://onestreet.org/documents/TrafficsHumanToll.pdf

UK DFT (Department for Transport) (2014a) Social impact appraisal, TAG Unit A4.1. Available from https://www.gov.uk/government/publications/webtag-tag-unit-a4-1-social-impact-appraisal

UK DFT (Department for Transport) (2014b) Distributional impact appraisal, TAG Unit A4.2. Available from https://www.gov.uk/government/publications/webtag-tag-unit-a4-2-distributional-impact-appraisal

US DOT (US Department of Transport) (1996) Community impact assessment: a quick reference for transportation. US DOT, Washington D.C. Available from http://www.fhwa.dot.gov/livability/cia/ quick reference/index.cfm

Van Kamp, I., Davies, H. (2013) Noise and health in vulnerable groups: a review. Noise and Health 15 (64), 153-159.

Willis, K G., Garrod, G D. (1999). Externalities from extraction of aggregates regulation by tax of land-use controls. Resources Policy 25 (2), 77-86.

WHO (World Health Organization) (2005) Health effects of transport-related air pollution. WHO, Copenhagen. Available from http://www.euro.who.int/_data/assets/pdf_file/0006/74715/E86650.pdf

Yamazaki, S., Sokejima, S., Nitta, H., Nakayama, T., Fukuhara, S. (2005) Living close to automobile traffic and quality of life in Japan: a population-based survey. International Journal of Environmental Health Research 15 (1), 1-9. 